\title{
The good, the bad and the ugly: what bibliometrics tells us about Romanian research
}

\author{
Mihai Constantinescu \\ PhDc, University of Bucharest, Faculty of Letters \\ E-mail constantin.mihai.escu@gmail.com
}

This study uses bibliometric indicators to show the evolution of Romanian research in the 2007-2015 interval. It focuses on the number of published citable items, citations received by these items and the relationship between these two indicators in order to highlight the trends that define Romanian research.

Keywords: bibliometrics; citations; Romania; research

\section{Introduction}

Bibliometrics has been used in research evaluation for several decades. Although it is not a full proof method and only takes into account quantitative aspects of research, it remains an important method of evaluating research. Different bibliometric indicators have been used in evaluating universities, researchers, academia, journals, publishing houses and national research performance.

This paper aims to analyse the evolution of Romanian scientific output during the first eight years after joining the European Union (2007-2015). For the purpose of this study, we will focus on three main aspects, the first two being the total number of citable items published and total number of citations received. During our research, we came across interesting data showing a strong correlation between the number of papers published in certain journals and the total number of papers published in the field of those journals. This will constitute the third aspect analysed in our paper.

We have found a surprisingly small number of published similar studies. Although bibliometric studies regarding (among other issues) Romanian research have been published (Kozak et al 2015), we have not found any regarding the 2007-2015 interval, nor have we found studies focusing on the same subjects as the present study.

\section{Methodology}

The data used in this study was extracted from the Science Citation Index (S.C.I.), Social Sciences Citation Index (S.S.C.I) and Arts and Humanities Index (A.H.I.) from the Web of Science Core Collection database in December 2016. The interval for which the data was extracted is between 2007 and 2015. Only documents defined as citable items (articles and reviews) have been taken into account.

Because of the nature of the databases (continuously updated), the data extracted here will almost certainly differ from data extracted in a different moment, especially for the last year of the analysis.

All the analyses presented here have been conducted within the above specified databases, therefore this paper should not be viewed as an image of the Romanian research in its entirety, but as an image of the research indexed in the specified databases. This study is subject to all the known issues regarding the Web of Science database, including, for example, the irreproducibility of data (Rossner et al 2007).

Revista Română de Biblioteconomie şi Ştiința Informării = Romanian Journal of Library and Information Science ISSN 1841-1940 • Volume 13 Issue 12017 pp. 3-10

This work is licensed under a Creative Commons Attribution-NonCommercial-NoDerivatives 4.0 International License 


\section{Results}

\subsection{Total citable items}

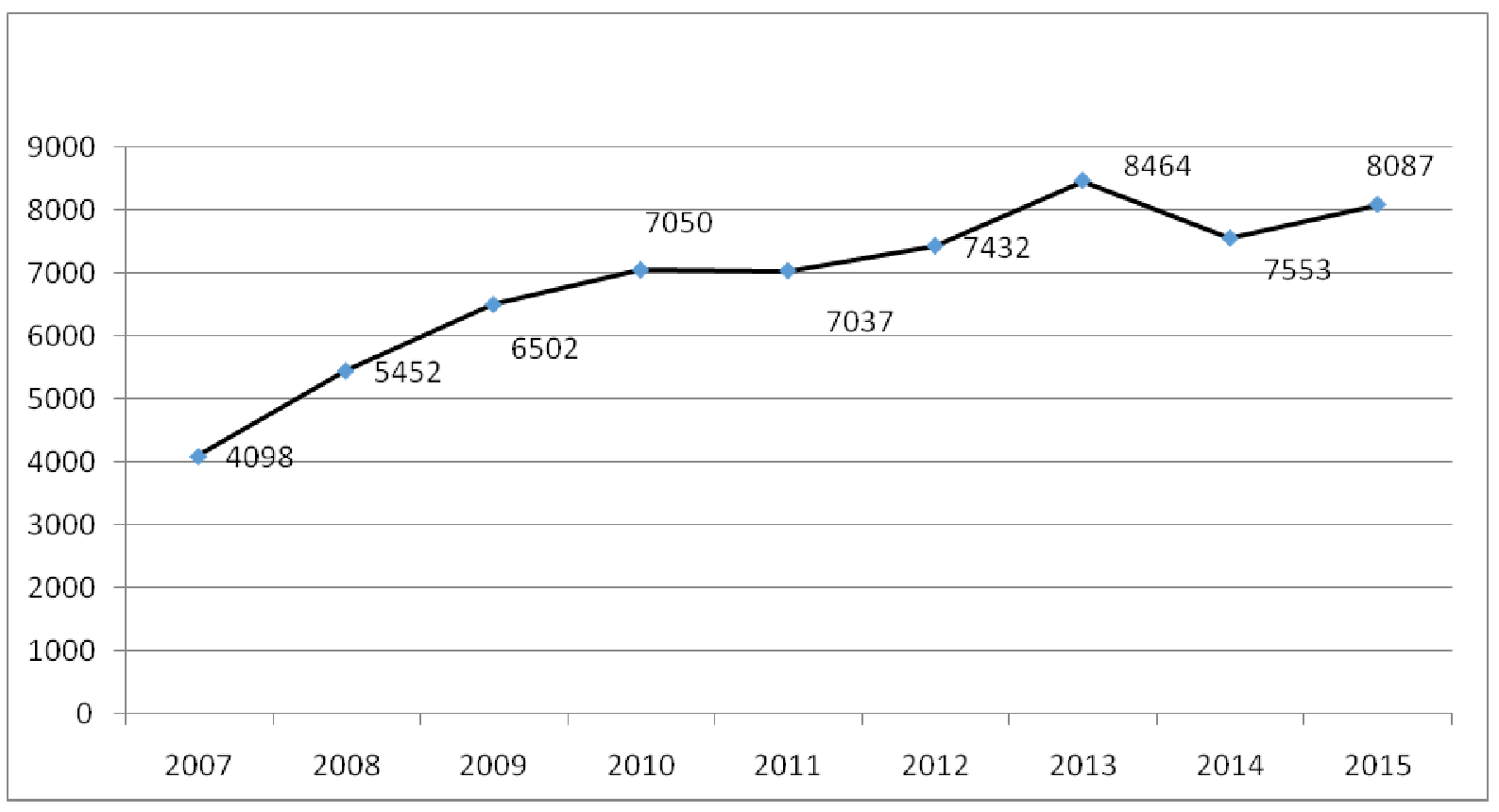

Fig. 1 Total citable items

Between 2007 and 2015, 61675 articles indexed in Web of Science have been published by the Romanian researchers (see Appendix 1). The number of articles increased from 4098 in 2007 to about 8000 in recent years (see Fig.1). The most significant increase occurred at the beginning of the reviewed interval, between 2007 and 2008, and represented a 33.04\% increase compared to the previous year (1354 articles). We can also observe two periods of decrease in the number of articles, in 2011 compared to 2010 (a decrease of 13 articles) and in the year 2014 compared to 2013 (a decrease of 911 articles).

The first four years are characterized by a rapid increase in the number of published papers (an increase of almost 3,000 articles between 2007 and 2010), while the second period is characterized by a slower growth, registering an increase of only 1,000 articles during the $2010-2015$ period. During this interval, the highest number of articles published is reached - 8464 - in 2013, but also the steepest decline in number of published articles - 10.76\% decrease in 2014.

At a closer look, we can see that about $75 \%$ of the total increase in number of articles (for the 2007-2015 interval) occurred in the first three years, while the last five accounted for the rest.

\subsection{Citations and self-citations}

Fig. 2 shows that the number of citations received by articles published by Romanian researchers register a positive trend in the 2007-2012 interval, followed by a steep decline.

Although it is probable that the number of citations for the 2012-2015 interval will increase, we have to take into consideration the fact that, especially in the sciences, the novelty of the information is an important criterion, therefore the increase in number of citations for the 2013 2015 period will probably not be significant enough to stop the decline. 


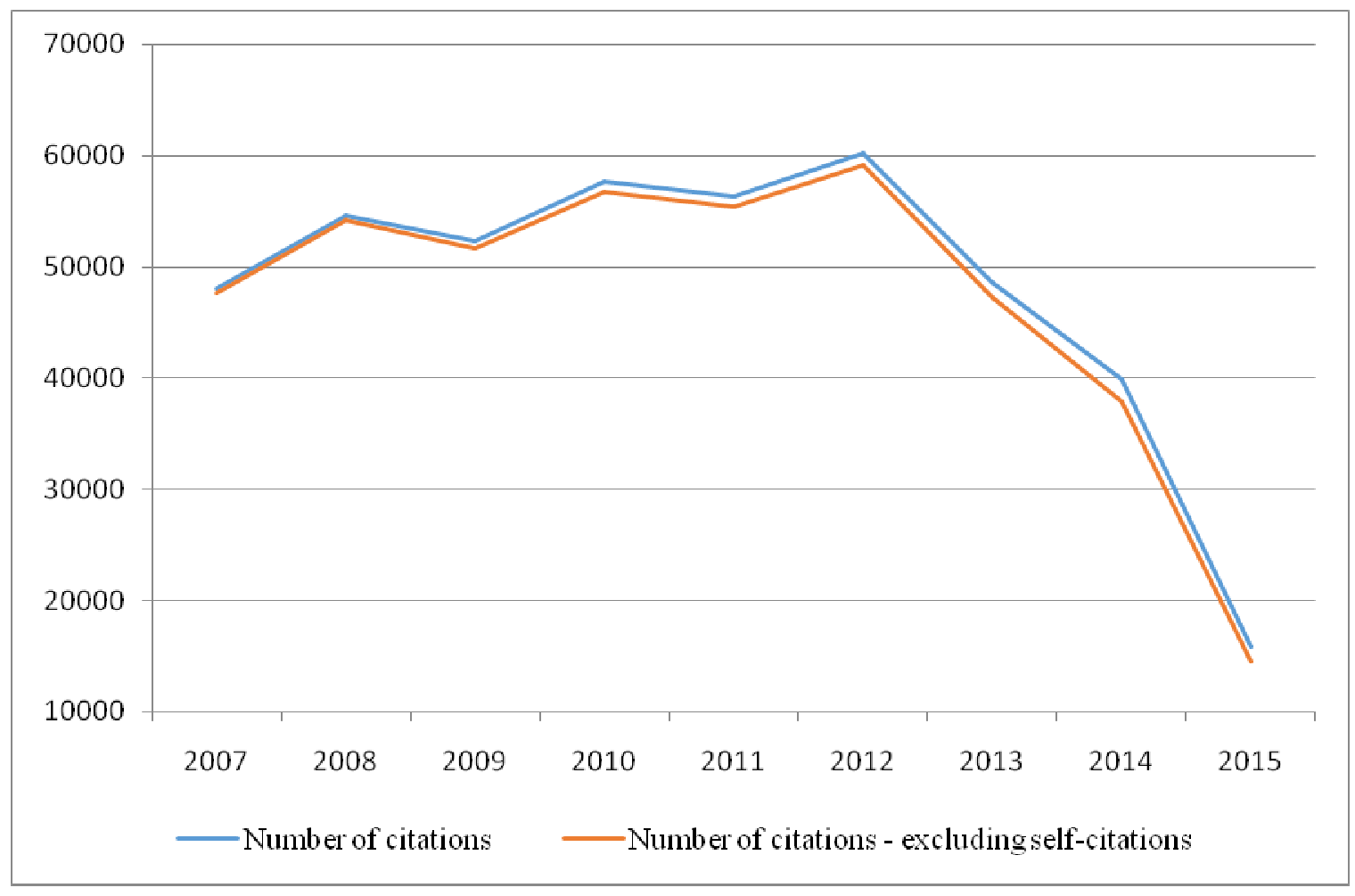

Fig. 2 Citations and self-citations

The significant increase in the number of citations (up to 2012) is a positive aspect of Romanian research, proving that the impact of scientific literature is growing. However, in order to have an accurate picture of the state of Romanian scientific literature, we have to compare the number of citations received to the number of published articles.

The graph above also shows the increase in the proportion of self-citations (as evidenced by the increasing space between total citations and number of citations without self-citations). This signals a potential quality issue regarding the Romanian scientific literature, but should be considered only as an indication and not irrefutable proof, as self-citations are not necessarily an indicative of low quality research.

\subsection{Citations per citable item}

When analysing the citation per citable item ratio (Fig. 3) we observe three stages: a decline from 2007 to 2009, a stagnation from 2009 to 2012, and a new phase of decline since 2013. Although new citations will be added for the latter period, especially for 2015 , where we can expect a significant increase, there remains a decline of 3.6 citations per item up to 2012 (when the citations per item ratio is only $69.25 \%$ of the 2007 ratio).

This highlights the fact that, although the total number of citations has increased, the increase was not proportional to the increase in the total number of articles published by researchers from Romania. 


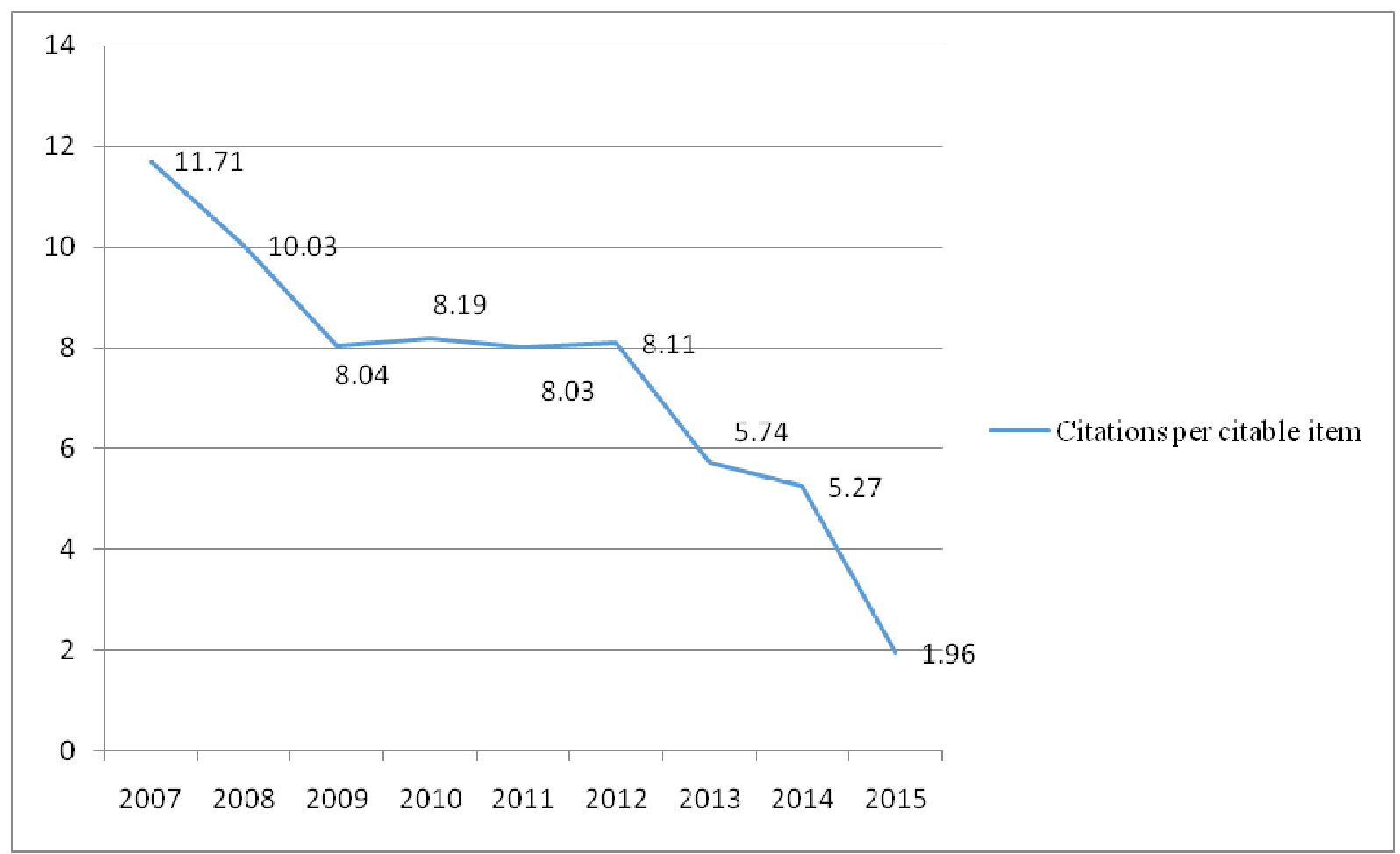

Fig. 3 Citations per citable item

\subsection{Journal - Scientific field correlation}

When analysing the evolution of the top Romanian scientific fields and journals (Appendix 2 and 3 ) we observed a strong correlation between the performance of two journals and the performance of the entire scientific fields of those journals. This is the case of the Journal of Optoelectronics and Advanced Materials (and the field Optics) and of Metalurgia Internațional (in Metallurgy, Metallurgical engineering).

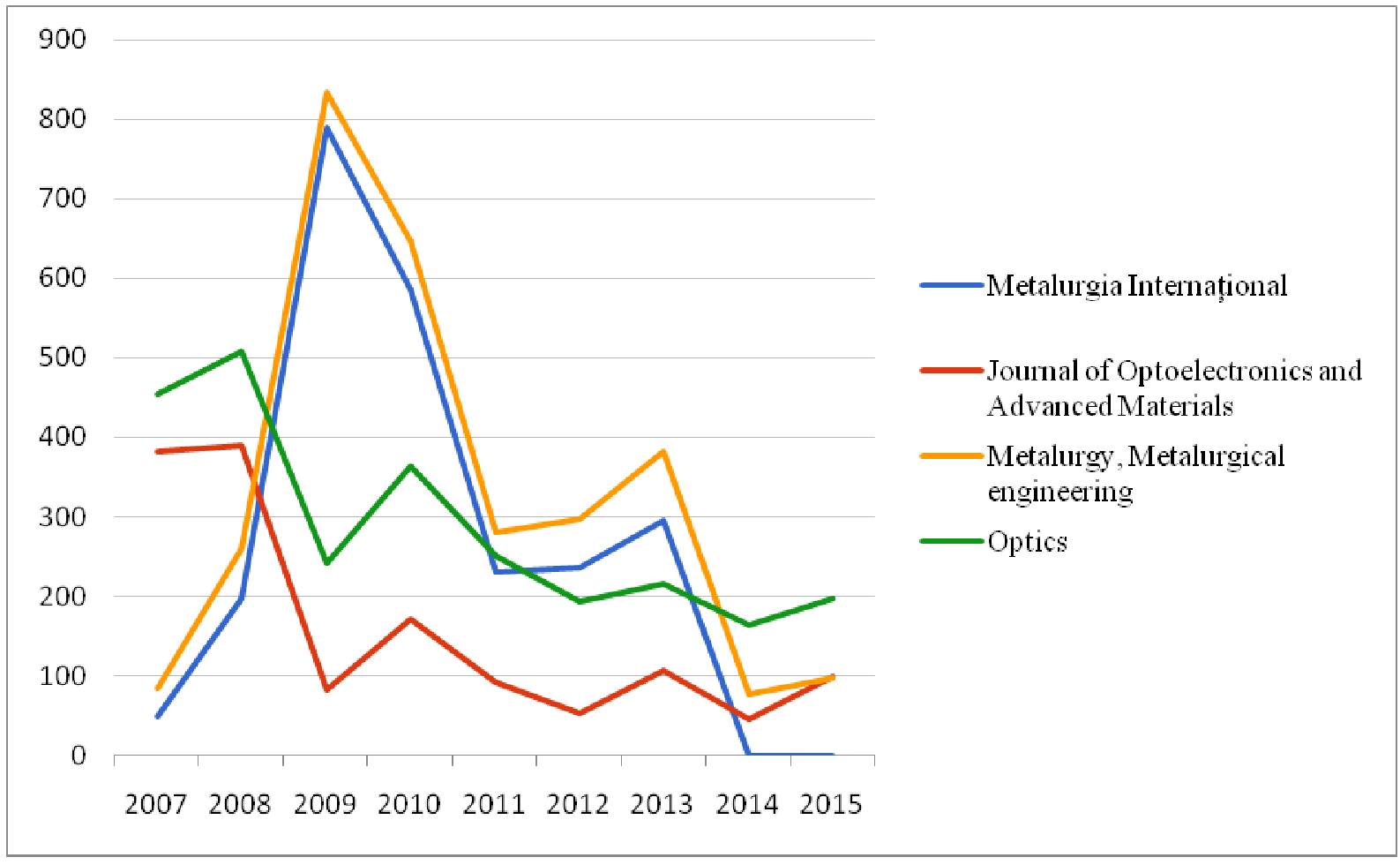

Fig. 4 Journal - scientific field correlation 
As can be observed in Fig. 4, both journal-field pairs show a strong correlation when comparing number of articles published. This relationship between the scientific field and the scientific output of one single journal warrants, in our opinion, further investigation. In both cases, we can observe a significant decrease in the number of published articles. The decrease from 508 articles published in the field Optics in 2008 to 241 in 2009 is hardly explainable, especially if we consider that this decline continues even further in the following years, albeit at a slower pace, reaching 198 published articles in 2015 (43.61\% of the articles published in 2007 and only 38.97\% of 2008). The Journal of Optoelectronics and Advanced Materials registers a corresponding decline from a maximum of 390 articles in 2008 to 82 in 2009, reaching 99 articles in 2015.

We can observe a similar issue in the case of Metallurgy, Metallurgical engineering: here, the number of articles decreases from 834 items in 2009 to 97 articles in 2015, thus totalling in the last year of our interval only $11.63 \%$ of the articles published in the year with the highest scientific output (2009). This steep decline (and also the steep increase in number of articles from 2007 to 2009 - a 1004.8\% increase) poses serious questions about the quality of articles published in this area and cannot be explained by a natural decrease in interest in the field. Similarly, the journal Metalurgia Internaţional has an increase in articles published from 49 in 2007 to 789 in 2009 - a $1610.2 \%$ increase - followed by a steep decline that culminated with the exclusion of the journal from the Science Citation Index after it was proven that Metalurgia Internațional did not perform peer review (Weber-Wulff 2013).

We consider this dependence of the Romanian scientific fields to the performances of single journals to be a possible indicator of problems regarding the quality of articles published in those fields. If research in these areas would have been competitive, the sharp drop in the number of articles published in these journals would have not affected the national scientific production, as researchers should have been able to publish elsewhere. This indicates the possibility that researchers did not manage to get their works published in other journals.

\section{Conclusions}

The role of bibliometrics is no longer limited to that of document selection, but has transformed into one of research evaluation for journals, researchers, academics or research projects. However, no current bibliometric indicator provides qualitative information. What they provide are quantitative information (primarily about number of documents and citations), that is interpreted as an indicator of quality. Moreover, these quantitative methods of evaluation have variable applicability depending on the scientific field and results vary depending on the indicator and bibliometric database used. Furthermore, the ever-increasing importance given to bibliometric indicators has also led to the emergence of numerous means of manipulating the indicators (Martin 2016).

Romanian research has made substantial progress, but the data we have indicates that those improvements are quantitative and not qualitative. We have observed important increases in both the number of articles published (about twice as many per year) and citations received (up to 2012). However, the increase in citations received is not proportional to the increase in the total number of articles. Relative to the number of papers published, citations received by Romanian researchers have been in decline, the number of citations per item in 2014 reaching only half ofthat registered in 2007. The usage of quantitative criteria (such as number of articles published) in academia evaluation may have led to an inflation of works that count towards fulfilling academic performance criteria but have a smaller impact in the scientific world.

A particularly problematic aspect regarding the evolution of the Romanian research in this period is the importance that certain journals seem to have on Romanian research in its entirety. For example, Metalurgia Internațional publishes, in 2009, 12.13\% of all Romanian articles (see Appendix 1 and 3). We consider this to be an extremely high percentage, especially given the 
known issues regarding the journal. Although it has been excluded from the Science Citation Index, all the articles published until its exclusion are still indexed, despite the unnatural growth in number of articles - $1610.2 \%$ in two years - that should have warranted a further investigation into the publishing history of this journal.

Further investigation seems also necessary when looking upon fields such as Optics, where the variation of published articles per year - from 508 to 241 in one year - is not justifiable by a normal decrease of interest in that field.

The last two examples show us a different usage for bibliometrics, one not oriented towards classifying articles, journals or research but towards identifying patterns in research publication. These patterns can be used as an early warning system that will enable us to identify issues much faster than we currently do.

Despite the evidence shown here, we stress the fact that using bibliometric indicators is only one of the necessary steps in evaluating research.

The aspects studied in this paper show that Romanian research is, from a quantitative point of view, on a positive trend. However, the research seems to be oriented more towards publishing papers and less towards making an impact. The possibility that entire fields of research are heavily influenced by only one journal casts a shadow of doubt that needs to be addressed. We believe that a shift towards encouraging the impact of research more than the publishing of articles should take place in order to ensure a positive future for the Romanian research.

\section{References}

Kozak, M., Bornmann, L. and Leydesdorff, L. (2014) How have the Eastern European countries of the former Warsaw Pact developed since 1990? A bibliometric study, Scientometrics, 102(2), pp.1101-1117 available: https://link.springer.com/article/10.1007/s11192-014-1439-8 [accessed 20 March 2017].

Martin B.R. (2016) Editors' JIF-boosting stratagems - Which are appropriate and which not?, Research Policy, 45(1), pp. 1-7 available: http://dx.doi.org/10.1016/j.respol.2015.09.001 [accessed 20 March 2017].

National Science Foundation (2016). Science and Engineering indicators, Arlington, VA: National Science Foundation.

Rossner, M., Van Epps, H. and Hill, E. (2007) Show me the data, Journal of Cell Biology, 179(6), pp. 1091-1092 available: https://dx.doi.org/10.1083\%2Fjcb.200711140 [accessed 20 March 2017].

Weber-Wulff, D. (2013) Junk Journal "Metalurgia International”, Copy, Shake, and Paste: A blog about plagiarism and scientific misconduct [online], December 30, available at: https://copyshake-paste.blogspot.ro/2013/12/junk-journal-metalurgia-international.html [accessed $20 \mathrm{March}$ 2017]. 
Appendix 1

\begin{tabular}{|c|c|}
\hline Year & Number of citable items \\
\hline 2007 & 4098 \\
\hline 2008 & 5452 \\
\hline 2009 & 6502 \\
\hline 2010 & 7050 \\
\hline 2011 & 7037 \\
\hline 2012 & 7432 \\
\hline 2013 & 8464 \\
\hline 2014 & 7553 \\
\hline 2015 & 8087 \\
\hline
\end{tabular}

Appendix 2

\begin{tabular}{|l|c|c|c|c|c|c|c|c|c|}
\hline Field/ Year & $\mathbf{2 0 0 7}$ & $\mathbf{2 0 0 8}$ & $\mathbf{2 0 0 9}$ & $\mathbf{2 0 1 0}$ & $\mathbf{2 0 1 1}$ & $\mathbf{2 0 1 2}$ & $\mathbf{2 0 1 3}$ & $\mathbf{2 0 1 4}$ & $\mathbf{2 0 1 5}$ \\
\hline Physics & 1136 & 1333 & 997 & 1115 & 1200 & 1231 & 1352 & 1104 & 1269 \\
\hline Chemistry & 905 & 961 & 1095 & 1072 & 1096 & 1175 & 1314 & 1220 & 1462 \\
\hline $\begin{array}{l}\text { Materials } \\
\text { science }\end{array}$ & 894 & 916 & 648 & 863 & 858 & 813 & 955 & 844 & 992 \\
\hline Engineering & 549 & 650 & 715 & 763 & 692 & 807 & 893 & 833 & 955 \\
\hline Mathematics & 455 & 665 & 797 & 794 & 776 & 767 & 877 & 798 & 807 \\
\hline Environment & 159 & 206 & 366 & 359 & 410 & 519 & 441 & 414 & 501 \\
\hline $\begin{array}{l}\text { Metallurgy, } \\
\text { metallurgical } \\
\text { engineering }\end{array}$ & 83 & 260 & 834 & 647 & 280 & 296 & 381 & 76 & 97 \\
\hline Optics & 454 & 508 & 241 & 364 & 251 & 193 & 216 & 164 & 198 \\
\hline $\begin{array}{l}\text { Science } \\
\text { Technology } \\
\text { Other Topics }\end{array}$ & 106 & 119 & 124 & 184 & 279 & 300 & 359 & 353 & 399 \\
\hline $\begin{array}{l}\text { Computer } \\
\text { science }\end{array}$ & 132 & 197 & 200 & 228 & 225 & 204 & 240 & 239 & 224 \\
\hline
\end{tabular}


Appendix 3

\begin{tabular}{|l|l|l|l|l|l|l|l|l|l|}
\hline \multicolumn{1}{|c|}{ Journal /Year } & $\mathbf{2 0 0 7}$ & $\mathbf{2 0 0 8}$ & $\mathbf{2 0 0 9}$ & $\mathbf{2 0 1 0}$ & $\mathbf{2 0 1 1}$ & $\mathbf{2 0 1 2}$ & $\mathbf{2 0 1 3}$ & $\mathbf{2 0 1 4}$ & $\mathbf{2 0 1 5}$ \\
\hline REVISTA DE CHIMIE & 278 & 271 & 271 & 252 & 223 & 244 & 274 & 295 & 420 \\
\hline $\begin{array}{l}\text { METALURGIA } \\
\text { INTERNATIONAL }\end{array}$ & 49 & 198 & 789 & 585 & 231 & 236 & 296 & 0 & 0 \\
\hline $\begin{array}{l}\text { JOURNAL OF } \\
\text { OPTOELECTRONICS } \\
\text { AND ADVANCED } \\
\text { MATERIALS }\end{array}$ & 382 & 390 & 82 & 172 & 92 & 52 & 107 & 45 & 99 \\
\hline $\begin{array}{l}\text { ENVIRONMENTAL } \\
\text { ENGINEERING AND } \\
\text { MANAGEMENT } \\
\text { JOURNAL }\end{array}$ & 50 & 84 & 199 & 180 & 146 & 190 & 153 & 125 & 127 \\
\hline $\begin{array}{l}\text { ROMANIAN JOURNAL } \\
\text { OF MORPHOLOGY } \\
\text { AND EMBRYOLOGY }\end{array}$ & 0 & 64 & 87 & 92 & 179 & 143 & 153 & 190 & 193 \\
\hline $\begin{array}{l}\text { REVUE ROUMAINE } \\
\text { DE CHIMIE }\end{array}$ & 132 & 123 & 118 & 128 & 127 & 110 & 78 & 97 & 84 \\
\hline $\begin{array}{l}\text { JOURNAL OF } \\
\text { ENVIRONMENTAL } \\
\text { PROTECTION AND } \\
\text { ECOLOGY }\end{array}$ & 42 & 56 & 48 & 67 & 135 & 182 & 106 & 81 & 111 \\
\hline $\begin{array}{l}\text { ROMANIAN REPORTS } \\
\text { IN PHYSICS }\end{array}$ & 50 & 86 & 61 & 78 & 102 & 110 & 99 & 76 & 92 \\
\hline $\begin{array}{l}\text { ROMANIAN } \\
\text { BIOTECHNOLOGICAL } \\
\text { LETTERS }\end{array}$ & 47 & 73 & 75 & 128 & 109 & 55 & 79 & 96 & 89 \\
\hline $\begin{array}{l}\text { MATERIALE } \\
\text { PLASTICE }\end{array}$ & 75 & 78 & 84 & 98 & 58 & 50 & 68 & 99 & 128 \\
\hline
\end{tabular}

